\title{
Performance Analysis of Gas Turbine Inlet Air Cooling Plant with Hybrid Indirect Evaporative Cooling and Absorption Chiller System
}

\author{
Amir Moradi Hamedani ${ }^{1}$, Gholamreza Salehi ${ }^{2, *}$, Mina Masoomi ${ }^{3}$, Mohammad Hasan Khoshgoftar Manesh ${ }^{4}$ \\ 1,2 Department of Mechanical Engineering, Faculty of engineering, Central Tehran Branch, Islamic Azad University, \\ Tehran, Iran \\ 3 Department of Energy Engineering and Economics, Faculty of Natural and Environment, Science and Research Branch, \\ Islamic Azad University, Tehran, Iran \\ ${ }^{4}$ Energy, Environment and Biological Systems Research Lab (EEBRlab), Division of Thermal Sciences and Energy \\ Systems, Department of Mechanical Engineering, Faculty of Technology \& Engineering, University of Qom, Qom, Iran \\ E-mail: ${ }^{1}$ moradi.amir1392@gmail.com; ${ }^{2}$ rezasalehi20@gmail.com; ${ }^{3}$ Masoomi.mina1991@gmail.com; \\ mh.khoshgoftar@gmail.com.
}

Received 14 December 2020, Revised 17 April 2021, Re-revised 22 May 2021, Accepted 30 May 2021

\begin{abstract}
To generate electricity, Gas Turbine Power Plants are extensively used around the world but their efficiency is negatively affected on hot days by ambient air temperatures. Efficiency and output power will decrease by $2 \%$ and $12.5 \%$ respectively at ambient temperature $40^{\circ} \mathrm{C}$ due to lower air density and the resulting increase in compressor specific work. Ordinarily, cooling down the intake air of the gas turbine is facilitated by employing a variety of Turbine Inlet Air Cooling Systems (TIACSs), depending on the plant's immediate weather conditions. This paper studies a new hybrid cooling method, combined cooling systems (Indirect Evaporative Cooling System (IECS) + Absorption Chiller), used for a $157 \mathrm{MW}$ gas power plant located in Asalouyeh in southern Iran. The Performance and ThermoEconomic analysis revealed that the annual power output can be $62,090 \mathrm{MW}$, the net income generated by the increased electricity sales can be $\$ 3,851,000$ for a $60 \%$ period of the year while Payback Period is found to be a year and six months. In comparison with Direct Evaporative Cooling system (DEC), the increased power output due to using Direct Evaporative Cooling system (DEC) is 12,290 MW and the net income generated by the increased electricity sales can be $\$ 116,899$ for a $60 \%$ period of the year while Payback Period is approximately 8 months.
\end{abstract}

Keywords: Gas Turbine; Turbine Inlet Air cooling System (TIACS); Indirect Evaporative Cooling System (IECS); Hybrid Cooling System; Thermo-Economic Analysis.

\section{Introduction}

Gas turbines are combustion engines often used to generate electricity. Capacity (i.e. generated power output) and efficiency of gas turbines decrease as the ambient temperatures grow. These engines in these turbines always transport a fixed volume of air while the power output depends on the total mass of the passing airflow [1]. Energy demand growth is high during warm weather conditions, and unfortunately, generated power output in gas turbines drops by about $30 \%$. More importantly, the efficiency can dwindle by $5 \%$ in all gas turbine systems during warm seasons [2]. Turbine Inlet Cooling (TIC) is a system of air conditioning for a gas turbine to maximize the gas turbine output across all ambient conditions and prevent loss of power output and energy efficiency reduction in all gas turbine systems [2].

This is to say that more electricity can be generated using less fuel while releasing fewer pollutants into the environment [3]. Turbine Inlet Air Cooling (TIC) technologies mainly involve the following methods [4]:

1. Direct Evaporative Cooling System

2. Spraying finely atomized water (fog) and fog production (Inlet air fogging)

3. Cooling system using mechanical chillers (vapour compression cycle) or Absorption chillers [4].
In Turbine Inlet Cooling (TIC), different methods can use depending on the indigenous weather conditions [4]. Each method is known by some advantages and disadvantages. $[4,3]$. For example, the fogging system has limited capacity and temperature of vapour depends on the power plant's location [5]. One of the major disadvantages of the Direct Evaporative Cooling (DEC) is its low efficiency and high water consumption. In addition, unevaporated water droplets in airflow can damage the compressor blades [6], or ice crystals can form on the surface of the compressor blades due to excessive cooling [6].

This paper introduces a cooling method (hybrid cooling system) for Asalouyeh Gas Power Plant (Iran) that consists of two cooling systems (IECS + Absorption Chiller) and that can result in relatively lower temperature and humidity. In hybrid cooling systems, the secondary airflow cooled by the DEC system enters the heat exchanger while the primary airflow cools down after crossing the secondary airflow and humidity is carried outside the system as well.

In another study, Marzouk and Hanafi [7] considered the direct evaporative evaporation (DEC) cooling system in Korymat power plant in south-eastern Egypt and showed that it is possible to obtain $27^{\circ} \mathrm{C}$ by solving equations with EES software. This could be used to increase the annual power output of gas turbines (GT) up to $86,118 \mathrm{MW}$ through turbine inlet evaporative cooling at an annual cost lower than that of 
mechanical chillers. They estimated the Payback Period would be about 0.66 years.

Najjar and Abubaker [1] showed that it is possible to obtain temperatures below $22^{\circ} \mathrm{C}$ by combining IECS system with either mechanical chillers or absorption chillers. They also found that the IECS system and the absorption chiller can be combined in hot and humid conditions to increase power output by $11.9 \%$ and efficiency by $98 \%$.

Through a Thermo-Economic analysis, Najjar and Abubaker [1] showed a combination of IECS and absorption chiller systems can be highly costly while it offers a short Payback Period (this period is 1 year in case of hot and humid weather conditions).

Ehyaei et al. [8] did Energy, Exergy and Environmental (3E) analyses for a $4900 \mathrm{KW}$ absorption chiller at $159 \mathrm{MW}$ Bushehr power plant-Iran and showed that applying a decrease from $37^{\circ} \mathrm{C}$ to $15^{\circ} \mathrm{C}$ during the hottest months of the year can increase the gas turbine power output from 137MW to $152 \mathrm{MW}$. In Iran, gas power plants and Combined Cycle Gas Turbine Plants (CHPs) are responsible for generating about 70,228 MW of electricity. As such, developing a proper cooling method can significantly help to both boost energy production and reduce pollution [9]. The present study explores the performance of gas turbine (GT) when a hybrid inlet cooling system is used. The main focus of this study are as follows:

- An introduction of Asalouyeh Gas Power Plant.

- A Thermodynamic model of Asalouyeh plant developed by EES software.

- An introduction of direct evaporative cooling system and absorption chiller.

- An introduction of Indirect Evaporative Cooling System (IECS) and its performance.

- An introduction of combined indirect evaporative cooling system and absorption chiller system (IECS + Abs-Chiller).

- EES solution.

- A Thermo-Economic analysis of the hybrid cooling system.

- Validation.

\subsection{The Influence of ambient temperatures on power} output and efficiency in gas turbines

Gas turbines are ordinarily designed for ISO conditions which include ambient temperature (of $15^{\circ} \mathrm{C}$ ) and relative humidity of $60 \%$. However, when the ambient temperature rises to $40{ }^{\circ} \mathrm{C}$ in summer, the GT efficiency is degraded to about $2 \%$ and the power output of $12.5 \%$ in comparison with ISO conditions [7]. The impact of rising ambient temperature on power output and thermal efficiency of a $157 \mathrm{MW}$ gas turbine is shown in Figure 1.

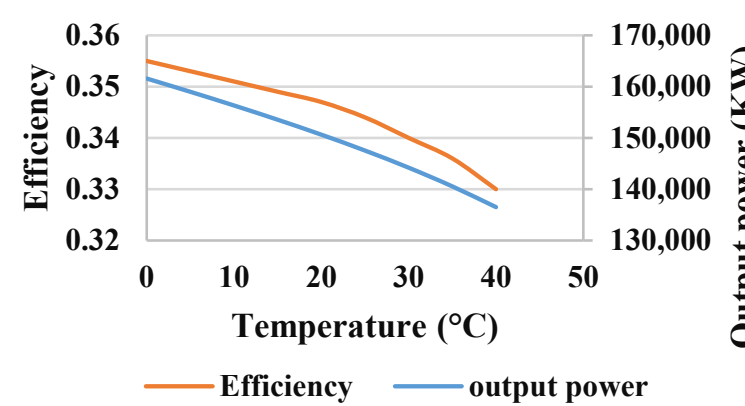

Figure 1. The impact of ambient air temperature on efficiency and power output in a gas turbine.

\section{Asalouyeh Gas Power Plant}

Asalouyeh Gas Power Plant is located $25 \mathrm{KMs}$ south of Pars Special Economic Energy Zone (PSEEZ) in Bushehr, Iran. This plant is a gas-fired power installation with a power production strength of $942 \mathrm{MW}$ in ISO conditions. It features $6 \times 157 \mathrm{MW}$ gas units of V94.2: the first and second units were installed in 2007 and other units were installed in 2008. The plant is mainly powered by natural gas and by Diesel fuel as the substitute fuel. Further details and specifications are found in Table 1.

The design of Turbine Inlet Cooling System (TICS) depends on plant's local conditions. For instance, the design of a cooling system for hot and humid climates differs from that of hot and dry climates. Therefore, the climate conditions in any given region need to be studied and determine prior to any installation operations [7]. Accordingly, this study on Asalouyeh Gas Power Plant draws on Asalouyeh's climate conditions as reported by Iran's Meteorological Organization (national weather service) in 2018 .

\section{Table 1. Gas turbine design information and other} specifications.

\begin{tabular}{ll}
\hline Item & Rate \\
\hline Gag turbine output (ISO), MW & 157 \\
Air inlet temperature (ISO), ${ }^{\circ} \mathrm{C}$ & 15 \\
Relative humidity (ISO), $\%$ & 60 \\
Average air mass flow rate, $\mathrm{kg} / \mathrm{s}$ & 504.40 \\
Ambient pressure, bar & 1.013 \\
Exhaust gases flow rate, $\mathrm{kg} / \mathrm{s}$ & 513.52 \\
Heat rate, $\mathrm{KJ} / \mathrm{KWh}$ & 10529 \\
Gas lower heating value, $\mathrm{KJ} / \mathrm{Kg}$ & 48820 \\
Compression ratio & 10 \\
Inlet temperature to turbine, ${ }^{\circ} \mathrm{C}$ & 1052 \\
Fuel gas mass flow rate, $\mathrm{kg} / \mathrm{s}$ & 8.802 \\
Efficiency, $\%$ & 34 \\
Compressor efficiency, $\%$ & 90 \\
Generator efficiency $\left(\boldsymbol{\eta}_{\mathrm{GE}}\right),{ }^{\circ} \%$ & 98 \\
Turbine mechanical efficiency $\left(\boldsymbol{\eta}_{\mathrm{ME}}\right), \%$ & 98 \\
T13, ${ }^{\circ} \mathrm{C}$ & 32 \\
T17, ${ }^{\circ} \mathrm{C}$ & 10 \\
T18, ${ }^{\circ} \mathrm{C}$ & 5.5 \\
T15, ${ }^{\circ} \mathrm{C}$ & 32 \\
Exhaust gases temperature, ${ }^{\circ} \mathrm{C}$ & 538 \\
\hline
\end{tabular}

The Figure 2 shows 3-hour temperature information units during a day per month over a period of one year. According to Figure 2, the lowest temperature was observed in March $\left(27^{\circ} \mathrm{C}\right)$ while the highest temperature belonged to July $\left(35^{\circ} \mathrm{C}\right)$. In addition, Figure 2 shows the average temperature for warm months of the year $\left(31^{\circ} \mathrm{C}\right)$. The Figure 3 shows the relative air humidity over a 3 -hour period per day per month for one year. Accordingly, the lowest relative humidity occurred in May (47\%) while the highest humidity belonged to August (69\%). The average relative humidity for the warm months of the year was $58 \%$. 


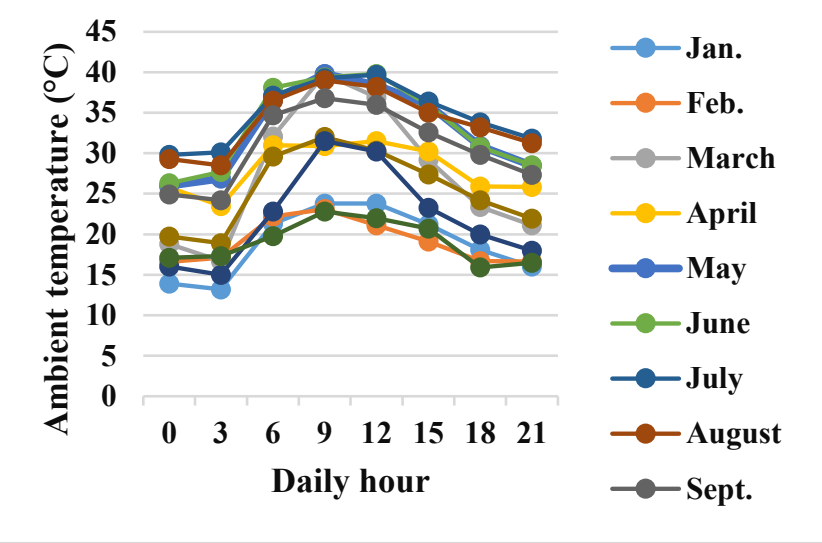

Figure 2. 3h temperature measured over a year.

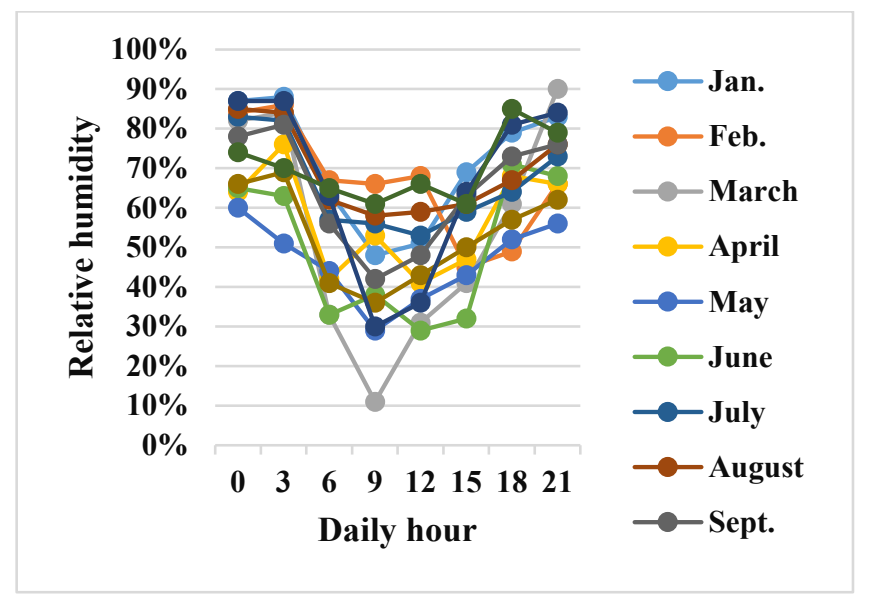

Figure 3. 3h relative humidity measured over a year.

\section{Thermodynamic Model of Gas Turbine}

Gas Turbines (GT) in power plants are made up of four parts: compressor, Combustion Chamber (CC), turbine and generator. Figure 4 presents a schematic diagram of a simple gas turbine. As shown in Figure 4, fresh atmospheric air is drawn into the circuit continuously and energy is added to the working fluid through the combustion process. The products of combustion expand down to the turbine, producing a shaft work output in the process. Combustion gases are eventually discharged through the exhaust into the atmosphere [7].

Efficiency in compressor and turbine is shown by $\eta_{C}$ and $\eta_{T}$, respectively. The ideal process and actual process are shown in the temperature-entropy diagram in black and dashed lines, respectively [7], (Figure 5).

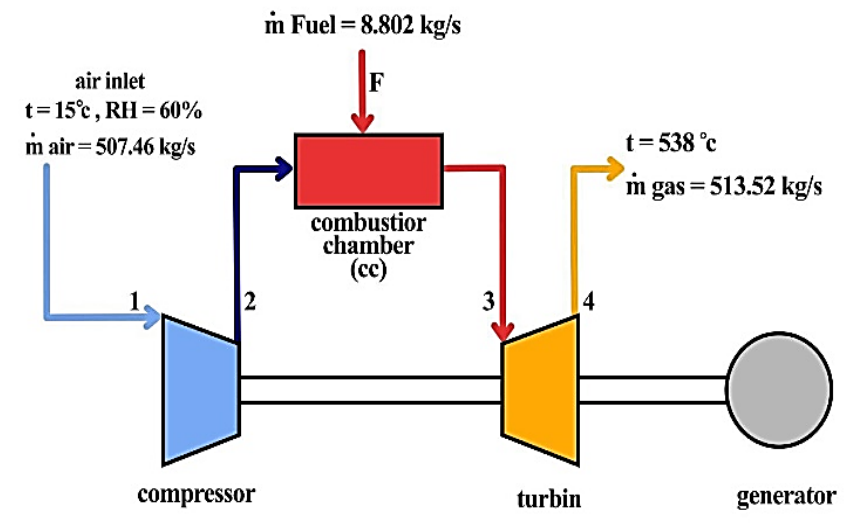

Figure 4. Components in a Gas Turbine.

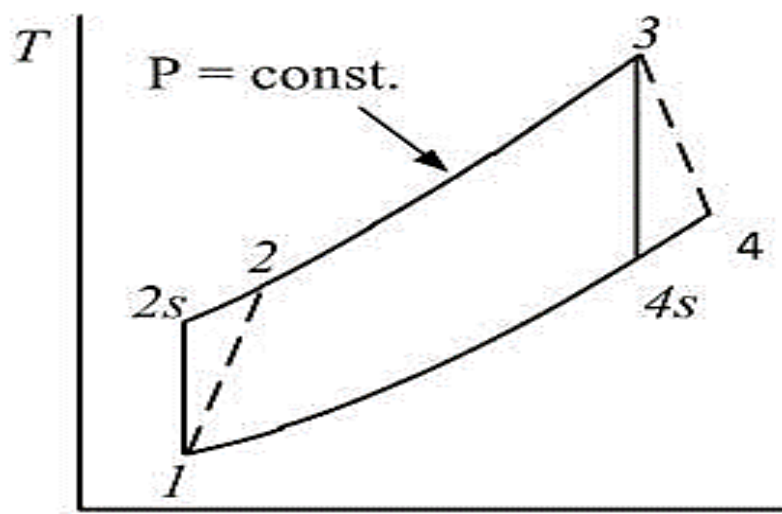

$S$

Figure 5. T-S diagram for the process in a Gas Turbine [7].

According to the diagram in Figure 5, the compression ratio in the compressor can be expressed by the following equation [7]:

$R_{P}=\frac{P_{2}}{P_{1}}$

Isentropic efficiency in compressor is approximately $80 \%$ to $90 \%$.

$\eta_{C}=\frac{T_{2 S}-T_{1}}{T_{2}-T_{1}}$

The exhaust air temperature in the compressor can be expressed by the following equations:

$$
\begin{aligned}
& T_{2}=\frac{T_{1}}{\eta_{C}} \cdot\left[\left(\frac{P_{2}}{P_{1}}\right)^{\frac{\gamma a-1}{\gamma a}}-1\right]+T_{1} \\
& o r \\
& \frac{T_{2}}{T_{1}}=\left(\frac{P_{2}}{P_{1}}\right)^{\frac{\gamma a-1}{\gamma a}}
\end{aligned}
$$

The compressor work can be expressed in the following relationship:

$W_{C}=\dot{m}_{a} \cdot C_{\text {Pa.avg }} \cdot\left(T_{2}-T_{1}\right)$ 
Where $\dot{m}_{a}$ is the inlet to the compressor and $C_{P a . a v g}$ is the specific heat of dry air at constant pressure.

The energy balance in the combustion chamber can be expressed in the following equation:

$\dot{m}_{a} \cdot C_{\text {Pa.avg }} \cdot T_{2}+\dot{m}_{f} \cdot L H V=\left(\dot{m}_{a}+\dot{m}_{f}\right) \cdot C_{\text {Pg.avg }} \cdot$

$T_{3}$

Where $\dot{m}_{T}$ represents the total mass flow rate obtained by combining airflow mass and fuel mass.

$\dot{m}_{T}=\dot{m}_{a}+\dot{m}_{f}$

The temperature of the turbine exhaust gas is calculated by the following equation:

$T_{4}=T_{3} \cdot\left[1-\eta_{T} \cdot\left(1-\frac{1}{R_{P} \frac{\gamma a-1}{\gamma a}}\right)\right]$

or

$T_{4}=T_{3} \cdot\left(1-\eta_{T}\right) \cdot R_{P . g}$

or

$T_{4}=T_{3}-\eta_{T} \cdot T_{3} \cdot\left[1-\left(\frac{1}{p_{3} / p_{4}}\right)^{\frac{\gamma g-1}{\gamma g}}\right]$

and also:

$R_{P . g}=\left(1-\frac{1}{R_{P}^{\frac{\gamma_{g}-1}{\gamma g}}}\right)$

Where $\eta_{T}$ is the isentropic efficiency of the turbine and $P_{4}$ is the pressure of the turbine exhaust gas.

The work in the turbine is calculated by the following equation:

$W_{T}=C_{P g . a v g} \cdot\left(T_{3}-T_{4}\right)$

or

$W_{T}=C_{P g . a v g} \cdot T_{3} \cdot \eta_{m} \cdot \frac{R_{P . g}}{\eta_{m}}$

Where $C_{P \text { g.avg }}$ represents the (average) specific heat of the exhaust gas passing through the turbine. The air-fuel ratio $\gamma$ is calculated from the following equation:

$\gamma=\frac{\dot{m}_{a}}{\dot{m}_{f}}$

The net output work is obtained from the following equation:

$W_{\text {net }}=W_{T}-W_{C}$

Here, the isentropic turbine efficiency is about $93 \%$.

$\eta_{T}=\frac{T_{3}-T_{4}}{T_{3}-T_{4 S}}$

The specific fuel consumption can be expressed in the following equation:

$S F C=\frac{360^{\circ}}{W_{\text {net }}}$

HR heat rate is the next parameter for the gas turbine and is expressed in the following equation:

$H R=S F C \cdot L H V$ or

$H R=\frac{3600}{\eta_{t h}}$

The heat added to the combustion chamber is calculated in the following equation:

$Q_{a d d}=C_{P g \cdot a v g} \cdot\left(T_{3}-T_{2}\right)$

The thermal efficiency of a gas turbine is expressed in the following equation:

$\eta_{t h}=\frac{3600}{S F C \cdot L H V}$

or

$\eta_{t h}=\frac{W_{\text {net }}}{Q_{\text {add }}}$

The turbine's power output is expressed in the following equation:

$P(M W)=\eta_{G E} \cdot \eta_{M E} \cdot \dot{m}_{a} \cdot W_{\text {net }}$

or

$P(M W)=\left(\dot{m}_{a}+\dot{m}_{f}\right) \cdot W_{n e t}$

Where $\eta_{G E}$ is generator efficiency (about 98\%) and $\eta_{M E}$ is a turbine's mechanical efficiency (about 98\%).

Further, the difference between the power output values in presence of cooling system and in absence of cooling system is calculated by the following equation:

$\Delta P=P_{\text {with cooling system }}-$

$P_{\text {without cooling system }}$

The Table 2 shows the characteristics of some of the variables used in this paper. The Table 3 shows the input parameters of the system which are essential for calculation by EES software.

Table 2. Specification of some variables.

\begin{tabular}{lll}
\hline Variable Title & Variable type & Measurement unit \\
\hline Pressure (P) & independent & $\mathrm{bar}$ \\
Temperature (T) & independent & $\mathrm{K}$ \\
Relative humidity & independent & $\%$ \\
Humid ratio (w) & dependent & - \\
Entropy (s) & dependent & $\mathrm{KJ} / \mathrm{Kg}-\mathrm{k}$ \\
Dewpoint (dp) & dependent & $\mathrm{K}$ \\
Enthalpy (h) & dependent & $\mathrm{KJ} / \mathrm{Kg}-\mathrm{k}$ \\
\hline
\end{tabular}

Table 3. Input parameters.

\begin{tabular}{lll}
\hline Input parameters & ISO condition & $\begin{array}{l}\text { During \%60 of a year } \\
\text { (average) }\end{array}$ \\
\hline $\mathbf{T}\left({ }^{\circ} \mathbf{C}\right)$ & 15 & 31 \\
$\mathbf{P}(\mathbf{b a r})$ & $1 / 013$ & $1 / 013$ \\
Relative humidity $(\%)$ & 60 & 58 \\
\hline
\end{tabular}




\section{Direct Evaporative Cooling System and Absorption} Chiller

\subsection{Direct evaporative cooling system (media)}

The direct evaporative cooling system (media) is very suitable for hot and dry weather because it cools ambient air temperature through latent evaporative heat: Temperature of Inlet Air is increased from the temperature of Dry Bulb Temperature of Inlet Air to Wet Bulb Temperature of Inlet Air. Through the procedure used in this cooling method, the sensible heat is converted to latent heat. Thus, the ambient air is cooled down as water evaporates from the wet media surface into the system [10]. This procedure is shown in Figure 6 along with a psychrometric diagram

After the cooling process in the media, inlet air temperature is calculated by the following equation $[7,11]$ :

$T_{a 2}=T_{a 1}-\epsilon\left(T_{a 1}-T_{w b}\right)$

Where $T_{a 1}$ is dry Bulb Temperature of Inlet Air, $T_{w b}$ is the Wet Bulb Temperature of Inlet Air and $\varepsilon$ is the cooler effectiveness which is assumed to be $90 \%$ in this paper.

The Cooling Load of the direct evaporative cooling (DEC) system is calculated by the following equation [11]:

$\dot{Q}_{C L}=\dot{m}_{a} \cdot C_{P . a v g} \cdot\left(T_{a 1}-T_{a 2}\right)$

Where $\dot{m}_{a}$ is the Air Flow Rate and $C_{P a . a v g}$ is the specific heat of the dry air with a constant pressure. In addition, the water vapour mass is calculated from the following equation [7]:

$R=\frac{V\left(\omega_{2}-\omega_{1}\right) \rho_{a}}{\rho_{w}}$

Where $\mathrm{v}$ is water volume $\left(\mathrm{m}^{3} / \mathrm{s}\right)$ and $\rho_{\text {air }}$ is dry air density and $\rho_{w}$ is water density.

The blow down rate can be determined from the blow down ratio which is [7]:

$E=\frac{\text { The blow down rate }}{\text { evaporation rate }}=\frac{B}{R}$

This ratio is calculated according to the E curve of water hardness. In this study, water hardness is assumed to be 150 PPm while the E ratio is assumed to be 4 .
$B=4 \cdot R$

Total water consumption $Q_{w}$ is the sum of evaporated water and blow down rate [7]:

$Q_{W}=B+R\left(m^{3} / s\right)$

\subsection{Absorption Chiller}

The absorption chiller is another way for the Gas Turbine Inlet Cooling (TIC). In this cooling method, the absorption chiller uses the exhaust heat from the Gas Turbine (GT). The atmosphere is cooled when the cooled water passes through the heat exchanger. The Figure 7 shows the structure of the heat exchanger in a chiller system and a psychrometric diagram [11].

The cooling load that is excluded from the airflow at the ambient conditions of the power plant can be calculated using the first law of thermodynamics [11].

$\dot{Q}_{C L}=\dot{m}_{a} \cdot\left[\left(h_{1}-h_{2}\right)-h_{f g} \cdot\left(\omega_{1}-\omega_{2}\right)\right]$

Where $\dot{m}_{a}$ represents the airflow rate, $h_{f g}$ is the latent heat of evaporation, and $\omega_{1}$ and $\omega_{2}$ show the inlet and outlet (the humidity ratio) of the evaporator system. One advantage of the absorption chiller cooling system is that it is not limited to ambient air temperatures [11].

\section{Indirect evaporative cooling system (IECS)}

An Indirect Evaporative Cooling System (IECS) is a relatively new method for Gas Turbine Inlet Cooling (GTIC) [1]. In fact, this method is a direct evaporative cooling system that uses evaporation for cooling in a way that no moisture is released into the gas turbine inlet (compressor) [12], thus protecting compressor blades and Combustion Chamber (CC) against possible damages due to moisture [13]. The Figure 8 shows an overall schematic representation of the indirect evaporative cooling system along with its psychrometric diagram. 8 shown.

In fact, an indirect evaporative cooling system is made up of a Direct Evaporative Cooling system (DEC) and an air-toair heat exchanger.
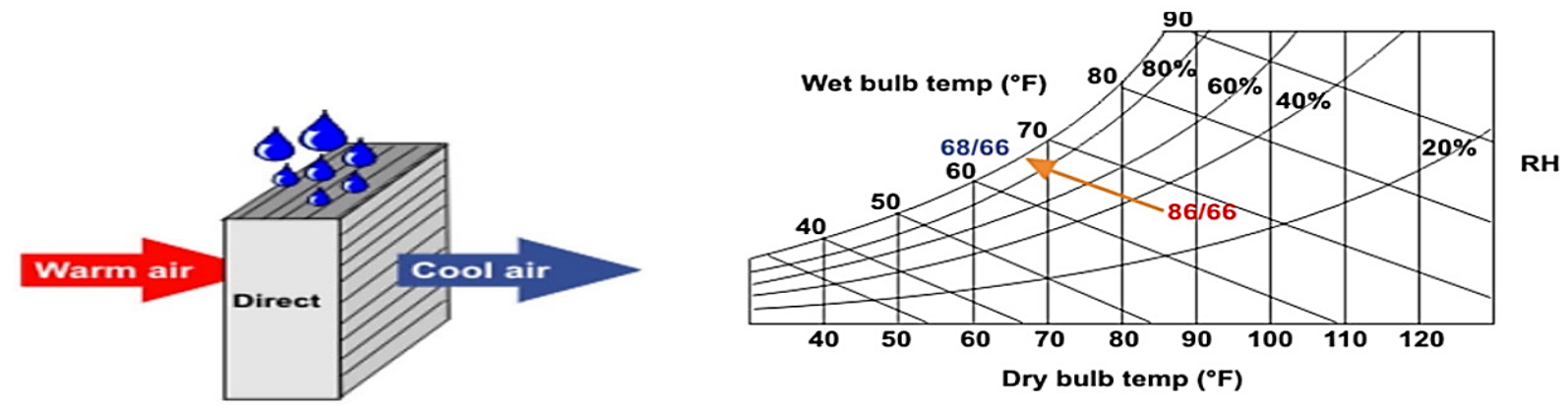

Figure 6. A Schematic representation of a Heat Exchanger in Direct Evaporative Cooling (DEC) system and its Psychrometric Diagram [10]. 

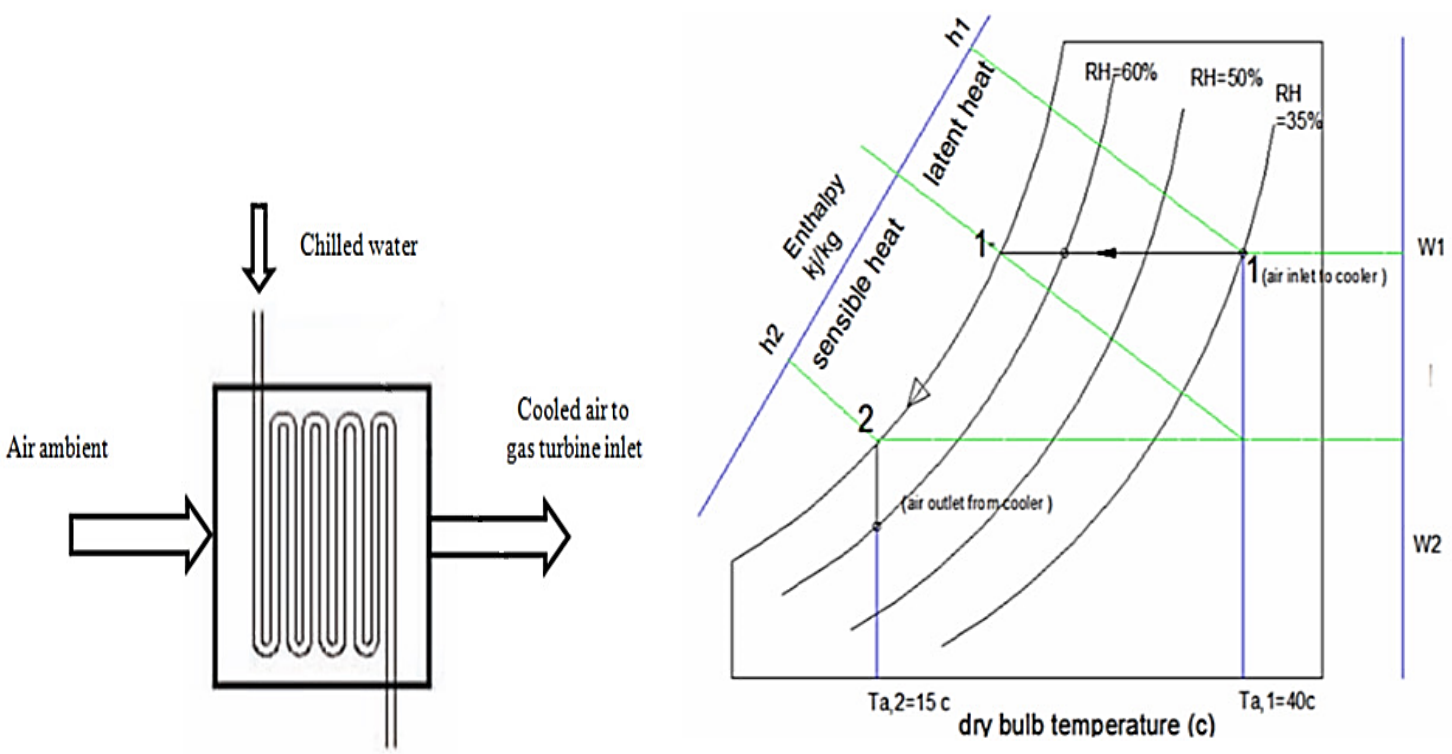

Figure 7. A Schematic Representation of Cooling Coil in a Chiller Cooling System and its Psychrometric Diagram [10].
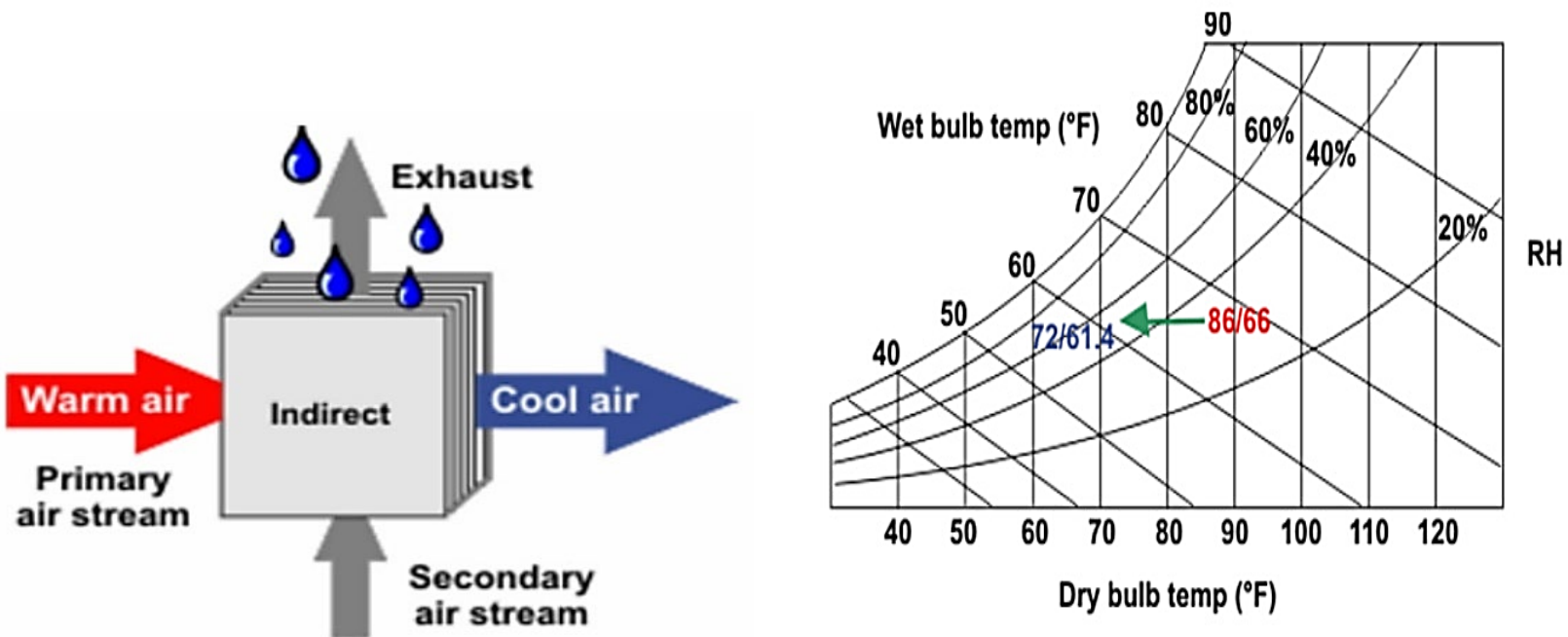

Figure 8. Indirect evaporative cooling system (IECS) with its psychrometric diagram.

\subsection{Indirect Evaporative Cooling System (IECS) Performance}

In an IECS, an airflow (called the primary airflow) is considerably cooled by a heat exchanger (no moisture added). The secondary airflow gets cooled by a Direct Evaporation Cooling (DEC) and then is directed to a heat exchanger in order to remove thermal energy from the primary air flow [12]. This air-to-air heat exchanger is used to cool the primary airflow by a Secondary airflow that has been already cooled. In this way, the primary airflow that exits the heat exchanger is a cooled flow free of moisture that can be used as the turbine inlet air. The Figure 9 shows a schematic representation of an IECS system performance [12].

In an IECS system, the heat exchanger can have two structures: tubular or plate. In an IECS system, both wet bulb and dry bulb are cooled. As mentioned above, no moisture is applied to the compressor for Turbine Inlet Cooling (TIC) in an indirect evaporative cooling. However, IECS is costlier than a direct evaporation system (DEC). IECS efficiency is $40 \%$ up to $80 \%$ [12].

The temperature of the secondary airflow that is emitted from a DEC system is obtained from the following equation (Figure 9) that can be solved using EES software [12].

$T_{S .2}=T_{S .1}-\eta_{D E C} \cdot\left(T_{S .1}-T_{S .1}^{\prime}\right)$

Where $T_{S .1}$ shows the Dry Bulb Temperature of Inlet Air in the DEC system, $T_{S .1}^{\prime}$ is the Wet Bulb Temperature of outlet Air from the DEC system and $T_{S, 2}$ is the Dry Bulb Temperature of outlet Air from DEC system.

The primary air temperature at the heat exchanger outlet is calculated from the following equation [12].

$T_{P .2}=T_{P .1}-\eta_{H X}\left(T_{P .1}-T_{S .2}\right)$ 
That is solved using EES software. Here, $T_{P .1}$ shows the Dry Bulb Temperature of Inlet Air at heat exchanger, $T_{P .2}$ represents Dry Bulb Temperature of outlet Air at the heat exchanger (compressor feed flow), $T_{S .2}$ shows the Dry Bulb Temperature of Inlet Air at the heat exchanger (DEC system outlet) and $\eta_{H X}$ is the heat exchanger effectiveness.

6. Combining the indirect evaporative cooling system and lithium bromide/water system

6.1 The types of hybrid cooling systems are [1]:

- A combination of the IECS and Vapour compression system (mechanical chiller).

- A combination of the IECS and absorption chiller system.

This paper is primarily focused on a hybrid cooling system (a combination of IECS and absorption chiller) and how it affects the efficiency and the power output of the gas turbine at Asalouyeh Gas Power Plant while offering an economic analysis of this installation.

Environmental conditions have a smaller impact on a combined IECS and absorption chiller system. However, the best environmental condition for such a system is warm and humid climates [1].

\subsection{Hypotheses for a combined IECS and absorption chiller system}

- The thermal energy required in a generator in the absorption chiller is supplied by the turbine outlet gases after heat is effectively reduced using a Heat Recovery Steam Generator (HRSG).

- $\quad$ Evaporator effectiveness is 0.9 .

- The evaporator outlet water temperature at the absorption chiller is around $6^{\circ} \mathrm{C}$.

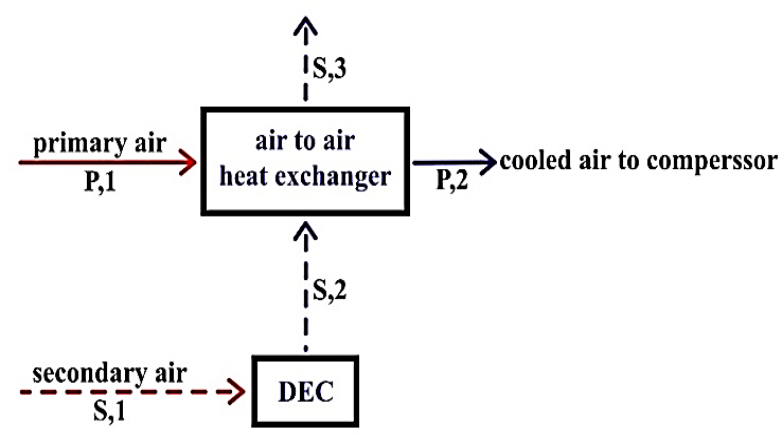

6.3 Performance of the indirect evaporative cooling system combined with an absorption chiller

The secondary cooled airflow emitted by the Direct Evaporative Cooling (DEC) system enters the heat exchanger (HX). At the same time, an atmospheric airflow (as a primary airflow) enters the heat exchanger. A collision between the primary airflow and the secondary airflow leads to removal of heat and moisture from former and the latter, respectively. As a result, the outlet flow of this (IECS) is cooled and less humid than the one coming from a Direct Evaporative Cooling (DEC) system. At this point, the temperature and humidity of this airflow are reduced after contacting the evaporator extracted from the absorption chiller system. This airflow can then be used to supply a gas turbine compressor. Figure 10 is a schematic representation of combined IECS and absorption chiller (i.e. hybrid cooling system).

\subsection{Psychometric Diagram}

Point P1 is the entry to the psychrometric diagram (Figure 11) with mean values for temperature and humidity determined. The red arrow marks the Direct Evaporation Cooling (DEC) system with a media system for cooling the inlet airflow. As moisture leaves the media surface, the cooling effect occurs along the constant enthalpy line. The relative humidity is $95 \%$, at S2 and humidity is emitted from S2 to S3 on the grey dashed line. The dark blue arrow represents the cooling action in primary airflow from P1 to $\mathrm{P} 2$. This is in fact the onset of the cooling operation in the heat exchanger (HX) with a constant humidity ratio and relative humidity of $58 \%$. The light blue arrow illustrates the decrease in temperature that happens along with the decrease in humidity ratio. At P3, this cooled airflow enters the gas turbine compressor.

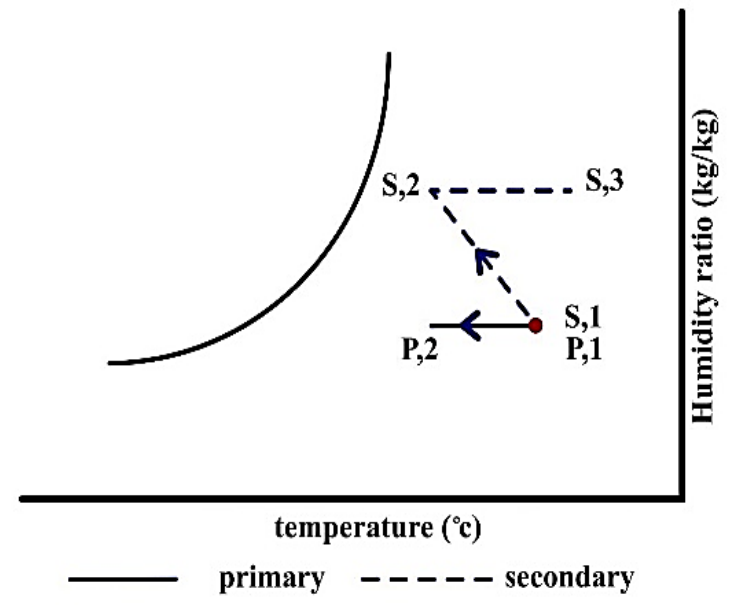

Figure 9. Schematic representation of the performance in an indirect evaporative cooling system (IECS) with a psychrometric diagram. 


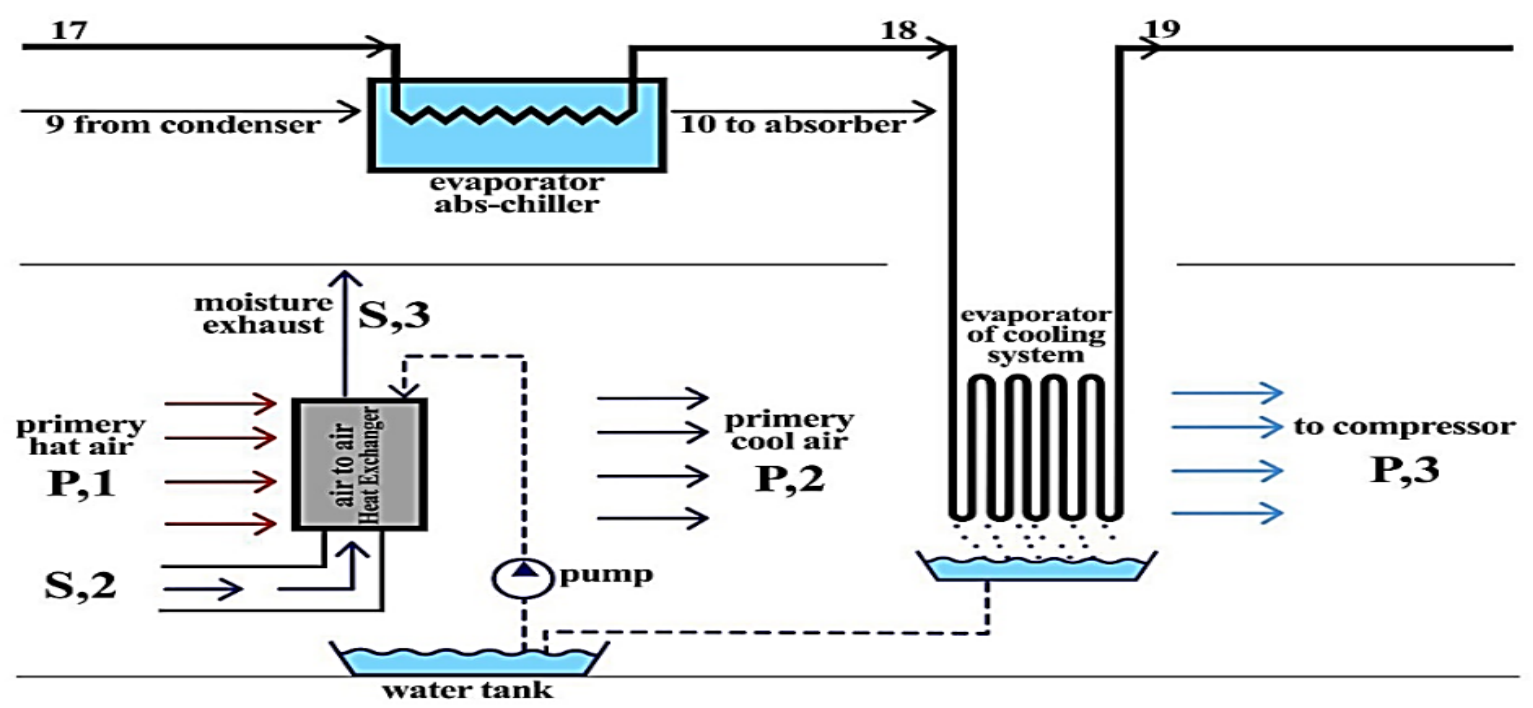

Figure 10. A combined IECS and absorption chiller system.

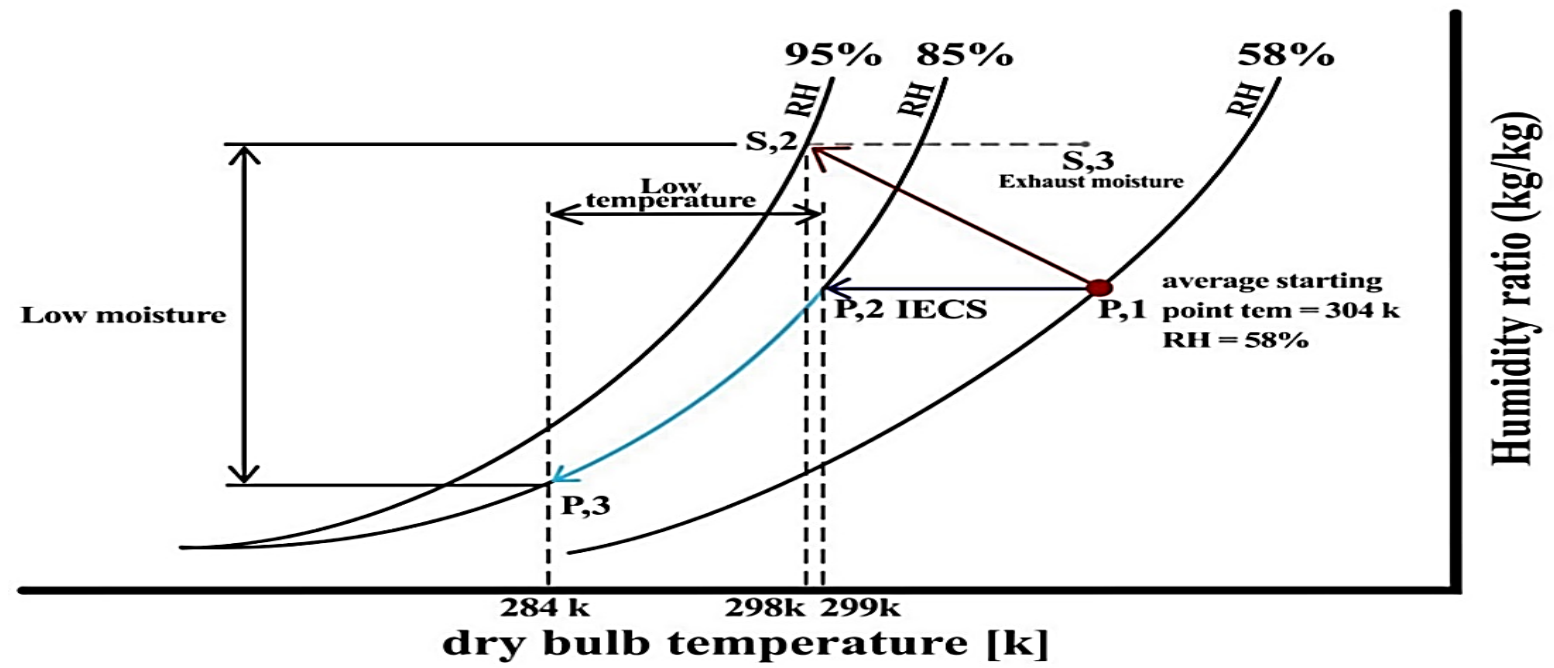

Figure 11. Psychrometric chart of cooling the inlet in a Hybrid system.

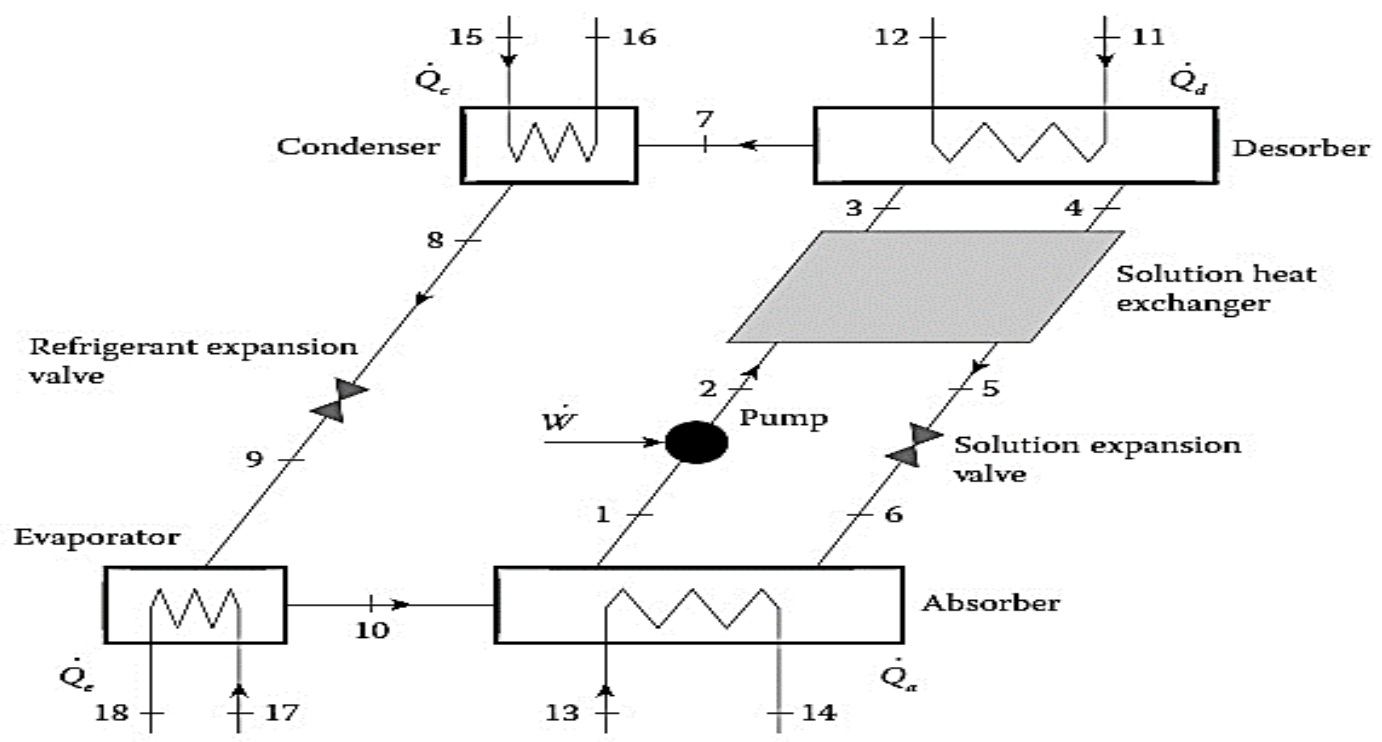

Figure 12. A schematic representation of a simple cycle in an absorption chiller [17]. 
6.5 A Theoretical Analysis of the Absorption Chiller System (Figure 12):

Evaporator:

$\dot{Q}_{\text {evap }}=\dot{m}_{\text {ref }} \cdot\left(h_{10}-h_{9}\right)$

$\dot{Q}_{\text {load }}=\dot{Q}_{\text {evap }}$

$\dot{m}_{r e f}=\frac{\dot{Q}_{\text {load }}}{h_{10}-h_{9}}$

Generator:

Equations for energy balance in generator:

$\dot{M}_{w e a k}=\frac{x_{4}-x_{7}}{x_{4}-x_{3}} \cdot \dot{m}_{r e f}$

$\dot{Q}_{G}=\dot{M}_{\text {weak }} \cdot\left(h_{4}-h_{3}\right)+\dot{m}_{r e f} \cdot\left(h_{7}-h_{4}\right)$

Condenser:

$\dot{Q}_{\text {cond }}=\dot{m}_{r e f} \cdot\left(h_{7}-h_{8}\right)$

Absorbent:

$\dot{Q}_{a b s}=\dot{M}_{\text {weak }} \cdot\left(h_{6}-h_{1}\right)+\dot{m}_{r e f} \cdot\left(h_{10}-h_{6}\right)$

And pump:

$\dot{W}_{\text {pump }}=\dot{M}_{\text {weak }} \cdot\left(P_{2}-P_{1}\right) \cdot v_{1}$

\section{EES solution}

The gas turbine model was solved using EES software. At the beginning of modeling the desired Gas turbine, the power production of the gas turbine was simulated in ISO conditions to evaluate the validation of solving equations. In standard state, the output power of software result was closed to ISO condition of gas turbine specifications. Average annual temperature and relative humidity of Assaluyeh entered the software, the result of simulation shows the output power of the gas turbine without the cooling system. The relative humidity and temperature gained from the simulation of the hybrid cooling system were replaced and the result was the output power of the gas turbine using the hybrid cooling system.

\section{A Thermo-Economic Analysis of Hybrid Cooling} System (IECS + Abs-Chiller)

In the case of using a hybrid cooling system to cool gas turbine inlet (TIC), the length of Recovery Period can be calculated. First, total investment should be estimated. For an IECS system, the total investment cost is $\$ 33 \mathrm{KW}^{-1}$ for expanding power output while the total investment cost for an absorption chiller system is roughly $\$ 477 \mathrm{KW}^{-1}[1]$.

\subsection{Extra fuel consumption cost}

In case of base conditions, fuel consumption at a power plant is $8.802 \mathrm{~kg} / \mathrm{s}$ and in case of power increase using a cooling system, fuel consumption is $8.907 \mathrm{~kg} / \mathrm{s}[14,15]$.

$1 \mathrm{~m}^{3}$ of natural gas is 1000 Rials in Iran for power plant consumption purposes.

fuel consumption in base condition

$$
\begin{aligned}
& =8.802 \mathrm{kgs}^{-1} \times 3600 \mathrm{sec} \\
& =31687.2 \mathrm{kgh}^{-1}
\end{aligned}
$$

fuel consumption with cooling system

$$
\begin{aligned}
& =8.907 \mathrm{kgs}^{-1} \times 3600 \mathrm{sec} \\
& =32065.2 \mathrm{kgh}^{-1}
\end{aligned}
$$

$\Delta_{\text {gas consumption }}=32065.2-31687.2$

$$
=387 \mathrm{kgh}^{-1}
$$

Where $\Delta_{\text {gas consumotion }}$ is the gas consumption per hour in an absorption chiller system. When converted to cubic meters, this amount becomes $527.932 \mathrm{~m}^{3} \mathrm{~h}$.

If $60 \%$ of the cooling system remains in operation during a year (or 5256 hours), the gas consumption cost will be about 2,774,810,592 Rials or USD23,123.42.

\subsection{Operation maintenance costs}

For an IECS+Absorption Chiller system, the Operation Maintenance costs are:

$2 \%$ of the entire investment cost in an absorption chillers system [16] and $4 \%$ of the entire investment cost in a direct evaporation system [7].

\subsection{Water Consumption}

The amount of evaporated water in a direct evaporative cooling system as well as the total water consumption is $0.1592 \mathrm{~m}^{3} / \mathrm{s}$ or $573.3 \mathrm{~m}^{3} / \mathrm{h}$. The price of water consumed in plants is 4000 Rials for one cubic meter. Thus, the cost of water consumed during the operating period of the cooling system is $\$ 100,433.3$ [7].

The annual income generated from the increased electricity sales can be calculated from the following equation. The unit price of increased electricity sales $\left(C_{e l s}\right)$ is estimated to be between 0.07 and 0.15 .

$$
\begin{aligned}
& \text { Annual saving power augmented } \\
& \qquad \begin{array}{l}
=\left(P_{\text {with cooling }}-P_{\text {without cooling }}\right) \\
\cdot C_{\text {els }}
\end{array}
\end{aligned}
$$

The Payback Period is calculated from the following equation:

Payback Period for IECS + Absorption chiller (year) 


\begin{tabular}{|c|c|c|c|c|}
\hline Parameters & $\begin{array}{c}\text { Najjar and } \\
\text { Abubaker [1] } \\
\text { (for } \\
\text { IECS+Absorptio } \\
\text { Chiller) }\end{array}$ & $\begin{array}{c}\text { Marzouk and Hanafi [7] } \\
\text { (for evaporative cooling } \\
\text { system) }\end{array}$ & $\begin{array}{c}\text { Current manuscript } \\
\text { (for } \\
\text { IECS+Absorption } \\
\text { Chiller) }\end{array}$ & $\begin{array}{l}\text { Current manuscript } \\
\text { (for evaporative } \\
\text { cooling system) }\end{array}$ \\
\hline payback period & $\begin{array}{c}1 / 079 \\
\text { (A Year) }\end{array}$ & $\begin{array}{c}0 / 66 \\
\text { (8 months) }\end{array}$ & $\begin{array}{l}1 / 59 \\
\text { (A Year and six } \\
\text { months) }\end{array}$ & $\begin{array}{c}\text { 0/692 (approximately } \\
9 \text { months) }\end{array}$ \\
\hline $\begin{array}{l}\text { Average power } \\
\text { increasing }\end{array}$ & $2 / 5 \%$ & $6 / 84 \%$ & $6 / 72 \%$ & $1 / 60 \%$ \\
\hline $\begin{array}{c}\text { Average } \\
\text { efficiency } \\
\text { increasing }(\eta)\end{array}$ & $2 \%$ & $1 / 5 \%$ & $2 / 4 \%$ & $2 / 94 \%$ \\
\hline
\end{tabular}

\section{Validation}

In order to validate the modeling results of the intended gas turbine performance analysis, the results of some published papers have been considered. For this purpose, the results of Najjar and Abubaker [1] and Marzouk and Hanafi [7] have been used to compare and validate the current manuscript results.

Najjar and Abubaker [1] showed that using the IECS + absorption Chiller system during hot and humid climate the average power increasing was about \%2.5 and Payback period achieved a year, on the other side the average efficiency of gas turbine was thrived $\% 2$.

In comparison with the current manuscript with using IECS + Absorption chiller system during hot and humid climate the average power increasing is about $\% 6.72$ and payback period is estimated about a year and six months, average efficiency increasing calculated approximately $\% 2.4$.

Marzouk and Hanafi [7] in their research revealed obviously through the evaporative cooling system during hot and humid climate in Egypt the average power and efficiency increasing was respectively $\% 6.84$ and $\% 1.5$. The payback period was evaluated for 8 months.

In opposite in this manuscript average power and efficiency increasing through evaporative cooling system during hot and humid climate are respectively $\% 1.60$ and $\% 2.94$, the payback Period is calculated about 9 months. The Table 4 shows the some prominent parameters that compared.

\section{Conclusion}

If a hybrid cooling system is used for $60 \%$ of a year (i.e. 5256 hours), the increased power output due to the hybrid cooling system is $62090 \mathrm{MW}$ approximately. As seen in the linear diagram in Figure 13, the greatest increased output in the gas turbine occurred in July (10.6\%) while the increased output in January is (3.57\%). The average increased output over a year is \%6.72. As shown in the linear diagram in Figure 14, the highest increase in thermal efficiency of gas turbine occurred in July $(4.49 \%)$ while and the lowest efficiency was observed in February (1.15\%). In addition, the average increase in thermal efficiency is $2.4 \%$.

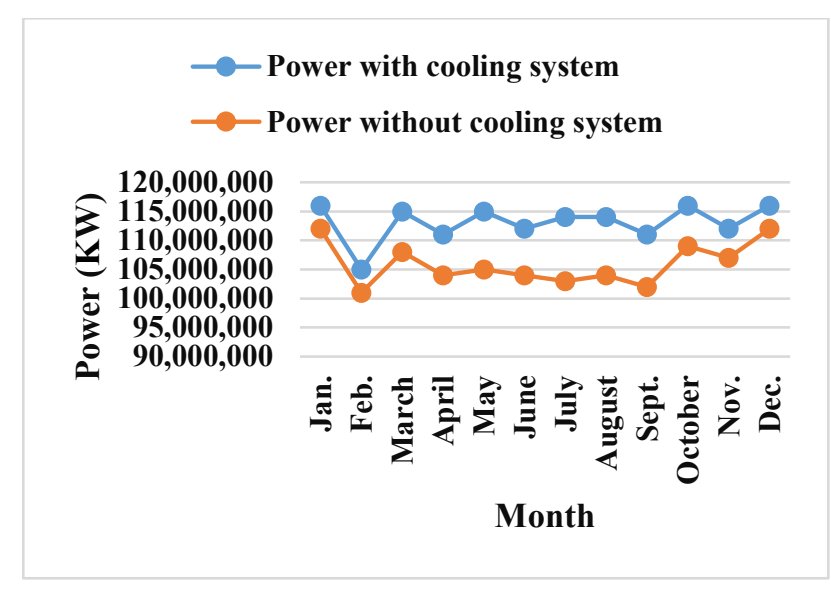

Figure 13. Power output with/without a hybrid cooling system.

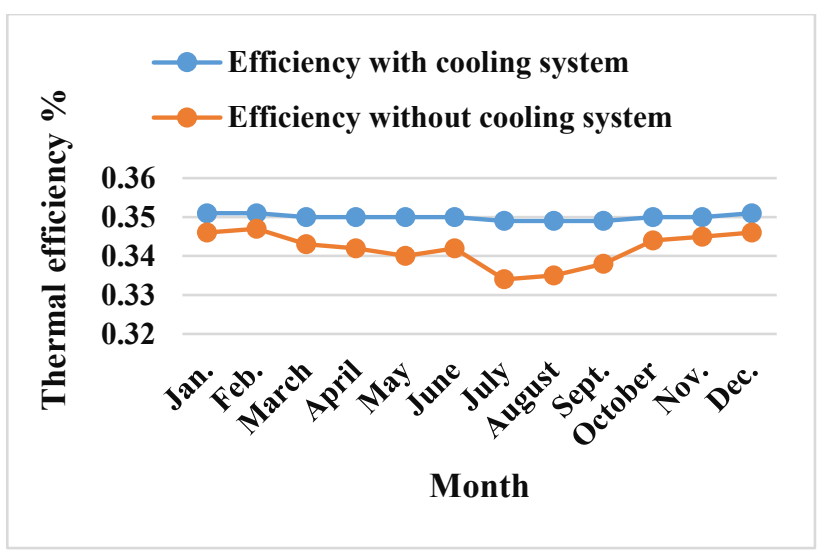

Figure 14. Thermal efficiency with/without a hybrid cooling system. 


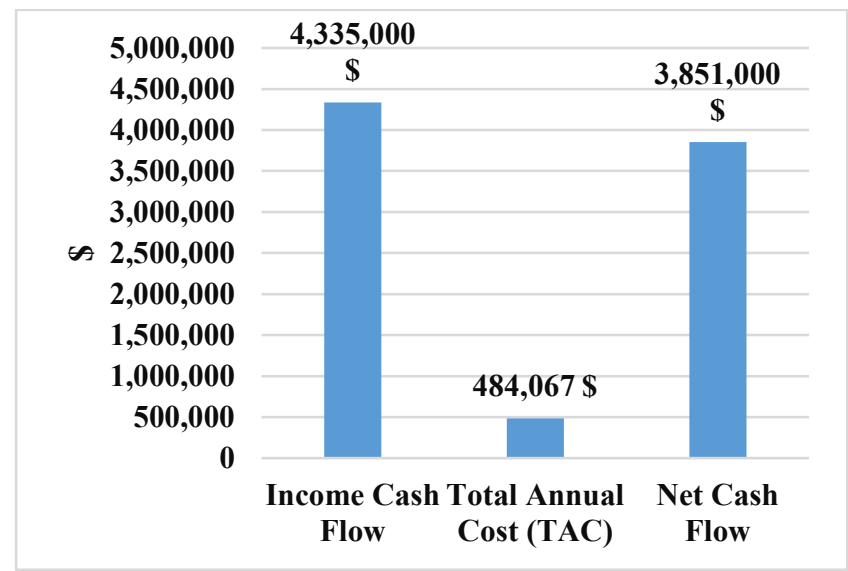

Figure 15. Annual income, Cost, and net Income.

This study of the Asalouyeh Gas Power Plant $(25 \mathrm{~km}$ south of Pars Special Economic Zone, Bushehr, Iran) showed that combining IECS and absorption chiller system with temperature and mean relative humidity of (inlet) $31 \mathrm{C}$ and $58 \%$ resulted in (outlet) $11^{\circ} \mathrm{C}$ and $85 \%$, respectively. The average increase in power output over a year is $6.75 \%$. Besides, Thermo-Economic analysis showed that using a Hybrid Turbine Inlet Cooling system (TIC) for $60 \%$ of the year would increase income from selling the increased electricity generated by the use of such a cooling system. According to Figure 15, this increase is $\$ 4,335,000$ while the total annual cost is $\$ 484,067$. Thus, total annual net income is $\$ 3,851,000$ and the Recovery Period is a year and six months, a significantly shorter period when compared to the Payback Period in case of combined IECS and vapour compressor chillers. Also, fuel consumption (natural gas) for generating this increased amount of power output due to the cooling system is much less than the fuel consumption for generating the same amount of power output without the cooling system.

In comparison with Direct Evaporative Cooling system (DEC), the increased power output due to using the DEC system is $12,290 \mathrm{MWh}$ and the net income generated by the increased electricity sales can be $\$ 116,899$ for a $60 \%$ period of the year while Payback Period estimated at 8 months.

\section{Acknowledgements}

We would like to express our gratitude to Malihe Baghali for her assistance.

\section{Nomenclature}

avg Average

B Blow Down Rate, $\left(\mathrm{m}^{3} / \mathrm{s}\right)$

$\mathrm{CC}$ Combustion Chamber

$C_{e l s} \quad$ Cost of selling excess electricity, (estimated between $0.07-0.15),(\$ / \mathrm{kwh})$

$\% 60$ a year $=5256$, (hours)

CHP Combine heat and Power

CL Cooling Load

DEC Direct Evaporative Cooling

E Blow Down Ratio

EES Engineering Equation Solver

GTIC Gas Turbine Inlet Cooling

GT Gas Turbine

$h_{f g} \quad$ latent heat of vaporization of water, $(\mathrm{KJ} / \mathrm{Kg})$

$h_{1} \quad$ Ambient Air Enthalpy At Cooler Inlet, $(\mathrm{KJ} / \mathrm{kg}-\mathrm{k})$

$h_{2} \quad$ Ambient Air Enthalpy At Cooler Outlet, (KJ/kg-k)

HX Heat Exchanger

Hybrid combination of two different things
IECS Indirect Evaporative Cooling System

ISO International Organization for Standardization

LHV Lower Fuel Heat Value, $(\mathrm{KJ} / \mathrm{kg})$

$\dot{m}_{a} \quad$ Air Mass Flow Rate At Inlet Of Cooler, $(\mathrm{kg} / \mathrm{s})$

$\dot{m}_{f} \quad$ Fuel Mass Flow Rate Without Cooling, $(\mathrm{kg} / \mathrm{s})$

$\dot{m}_{T} \quad$ Total mass flow rate, $(\mathrm{kg} / \mathrm{s})$

$\mathrm{P}, 1 \quad$ primary air of Heat Exchanger

$\mathrm{P}, 2$ primary cooled air from Heat Exchanger

$\mathrm{P}, 3$ final cooled air stream by Evaporator of cooling system

$\Delta \mathrm{p} \quad$ Difference Between Gas Turbine Output (without and with cooling), (MW)

$Q_{\text {add }} \quad$ Heat Added To Combustion Chamber, $(\mathrm{KJ} / \mathrm{Kg}-\mathrm{k})$

$\dot{Q} \quad$ Heat Transfer rate, $(\mathrm{KW})$

$Q_{W} \quad$ total water consumption, $\left(\mathrm{m}^{3} / \mathrm{s}\right)$

$\mathrm{R} \quad$ Evaporative Cooler Vaporization rate, $\left(\mathrm{m}^{3} / \mathrm{s}\right)$

RH Relative Humidity, (\%)

Rial National currency of Iran

SFC Specific Fuel Consumption, (kg/kwh)

$\mathrm{S}, 1$ secondary air of DEC system

S,2 secondary cooled air from DEC system

$\mathrm{S}, 3$ exhaust moisture from Heat Exchanger

TAC Total Annual Cost, (\$)

TIACS Turbine Inlet Air cooling System

TIC Turbine Inlet Cooling

$T_{a 1} \quad$ Ambient Air Temperature At Inlet, $\left({ }^{\circ} \mathrm{C}\right)$

$T_{a 2} \quad$ Ambient Air Temperature At Outlet, $\left({ }^{\circ} \mathrm{C}\right)$

$T_{w b} \quad$ Wet Bulb Temperature Of Inlet Air, $\left({ }^{\circ} \mathrm{C}\right)$

$\mathrm{V} \quad$ Air Flow Rate, $\left(\mathrm{m}^{3} / \mathrm{s}\right)$

$w_{1} \quad$ Humidity Ratio Of Air At Cooler Inlet, $(\mathrm{gm} / \mathrm{kg})$

$w_{2} \quad$ Humidity Ratio Of Air At Cooler Outlet, $(\mathrm{gm} / \mathrm{kg})$

$\mathrm{X}$ mass fraction $\mathrm{LiBr}(\%)$

\section{Greek symbols}

$\boldsymbol{\varepsilon} \quad$ Evaporative Cooler Efficiency

$\eta_{C} \quad$ Compressor isentropic efficiency, (\%)

$\eta_{G E} \quad$ Generator Efficiency, (\%)

$\eta_{M E} \quad$ Turbine Mechanical Efficiency, (\%)

$\eta_{t h} \quad$ Gas turbine thermal efficiency, (\%)

$\rho_{a} \quad$ Air Density, $\left(\mathrm{kg} / \mathrm{m}^{3}\right)$

$\rho_{w} \quad$ Water Density, $\left(\mathrm{kg} / \mathrm{m}^{3}\right)$

\section{References}

[1] Y. S. H. Najjar, A. M. Abubaker, "Indirect evaporative combined inlet air cooling with gas turbines for green power technology", International Journal of Refrigeration., 59, 235-250, 2015.

[2] D. V. Punwani, "Hybrid Systems For Cooling Turbine Inlet Air Preventing Capacity Loss And Energy Efficiency Reduction Of Combustion Turbine System", Proceeding of the ASME; Power Conference., 13-15, 2010, Chicago, Illinois, USA.

[3] P. Ivanova, O. Linkevics, A. Sauhats, "Cost- benefit analysis Of CHP plants taking into account air cooling technologies", 2017; 978-1-5386-3917-7/17/\$31.00 2017 IEEE.

[4] M. Farzaneh-Gord, M. Deymi-Dashtebayaz, "Effect of various inlet air cooling methods on gas turbine performance", Jornal of Energy., 36,1196-1205, 2011.

[5] http://www.albadronline.com/oldsite/books/49_GasTurb ineInlet.pdf. 
[6] R. Jassim, G. Zaki, B. Habeebullah, M. Alhazmy, "Thermo-Economic Analysis of Gas Turbines Power Plants with Cooled Air Intake", International Journal of Energy and Power Engineering., 4(4), 205-215, 2015.

[7] A. Marzouk, A. Hanafi, "Thermo-Economic Analysis of Inlet Air Cooling In Gas Turbine Plants", Journal of Power Technologies., 93(2), 90-99, 2013.

[8] M. A. Ehyaei, S. Hakimzadeh, N. Enadi, P. Ahmadi, "Exergy, Economic And Environment (3E) Analysis of Absorption chiller Inlet Air Cooler Used in Gas Turbine Power Plants", International Journal of Energy Reserch., 36 (4), 486-498, 2012.

[9] https://en.m.wikipedia.org/wiki/List_Of_Station_In_Iran

[10] A. P. Santos, C. R. Andrade, "Analysis of Gas Turbine Performance with Inlet Air Cooling Techniques Applied to Brazilian Sites"., J. Aerosp. Technol. Manag., Sao Jose dos Campos, Vol.4,No 3,pp.341-353, July,-Sep, 2012.

[11] A. Paula P. D. Santos, C. R. Andrade, Edson L. Zaparoli, "Comparison of Different Gas Turbine Inlet Air Cooling Methods", International Journal of Aerospace and Mechanical Engineering., Vol:6, No:1, 2012.
[12] J. K. Jain, D. A. Hindoliya, "Energy saving potential of indirect evaporative cooler under Indian climates", International Journal of Low-Carbon Technologies., 11, 193-198, 2016.

[13] M. A. Ehyaei, A. Mozafari, M. H. Alibiglou, "Exergy, economic \& environmental (3E) analysis of inlet for gas turbine power plant", Journal of Energy., 36, 68516861, 2011.

[14] S. M. Arabi, M. Aminy, H. Ghadamian, H. A. Ozgoli, B. Ahmadi, "Thermo-economic analysis of implementing fog-based cooling system in GE-F5 gas turbines (case study)", Journal of heat and Mass Transfer Research., 4, 73-81, 2017.

[15] S. M. Arabi, H. Ghadamian, M. Aminy, H. A. Ozgoli, B. Ahmadi, M. khodsiani, "Thermo- Economic Analysis of Absorption Chiller Integrated with a GE-F5 for Power Enhancement", Iranian Journal of Mechanical Engineering., Vol 19, No. 1, March 2018.

[16] C. Cimsit, I. T. Ozturk, O. Kincay, “Thermoeconomic optimization of $\mathrm{LiBr} / \mathrm{H} 2 \mathrm{O}-\mathrm{R} 134 \mathrm{a}$ compressionabsorption cascade refrigeration cycle", Applied Thermal Engineering., 76, 105-115, 2015.

[17] K. E. Herold, R. Radermacher, S. A. Klein, "Absorption Chiller and Heat Pumps”, USA, CRC Press., 2016. 